\title{
RHEOLOGICAL PROPERTIES OF COMPOSITIONS BASED ON MODIFIED POLYVINYL ALCOHOL
}

\author{
Volodymyr Krasinskyi', Oleh Suberlyak', Viktoria Antonuk', Tomasz Jachowicz² \\ 1 Lviv Polytechnic National University, Department of Chemical Technology and Plastics Processing, Bandera \\ 12 St., 79013 Lviv, Ukraine, e-mail: vkrasinsky82@gmail.com \\ 2 Lublin University of Technology, Faculty of Mechanical Engineering, Department of Polymer Processing, \\ Nadbystrzycka 36 St., 20-618 Lublin, Poland, e-mail: t.jachowicz@pollub.pl
}

Received: 2017.05.15

Accepted: 2017.08.01

Published: 2017.09.03

\begin{abstract}
The paper is dedicated to development of a method for producing structured waterproof films based on polyvinyl alcohol (PVA) and montmorillonite-polyvinylpyrrolidone mixture (MPM) to research the impact of borax, $\mathrm{pH}$-environment and MPM content on the rheological properties PVA solutions and water absorption capacity of films based on them. In the experimental studies it has been established that the montmorillonite- polyvinylpyrrolidone mixture significantly effects on viscosity the characteristics of the solution polyvinyl alcohol provided their mixing in the ultrasonic field. Composition of traces of sodium tetraborate in the aqueous solution eminent by the highest rates of viscosity. Also, designed compositions have a considerable influence on $\mathrm{pH}$ at the viscosity, particularly compositions obtained in weakly alkaline environment with higher values of relative viscosity than compositions obtained in neutral and acidic environments. Simultaneously, the best water resistance and mechanical properties of films is obtained in an acidic environment. The optimum from the standpoint of durability and water resistance is a composition of PVA:MPM = 12:1 and because, depending on the contents of the MPM and $\mathrm{pH}$ characteristics films based on PVA can be adjusted over a wide range, which would expand the scope.
\end{abstract}

Keywords: polyvinyl alcohol, montmorillonite-polyvinylpyrrolidone mixture, modifier, viscosity, exploitation characteristics, borax, heat treatment, film.

\section{INTRODUCTION}

Intercalation inorganic polymers in layered materials such as clay minerals - a promising method of obtaining new organic-inorganic nanostructures - supramolecular structures with specific molecular structure.

Layered nanocomposites based on polymer and layered silicate have a higher thermal stability, resistance to solvents and resistance to different environments permeability compared to conventional filled materials. Due dispersion of the filler at the nanoscale they are able to maintain light transmission of the polymer. In nanocomposites polyvinyl alcohol/ montmorillonite (PVA/MMT), especially at low concentrations layered silicate $(<10 \%)$ suitable for industrial use, transmission electron microscopy and RPDA show simultaneous number intercalated and stratified silicate layers. Nanocomposites PVA/MMT have a high light transmission even in the filler content, sufficient for the formation of layered nanocomposites. It is explained by the dispersion of particles in a layered silicate PVA matrix at the nanoscale.

Polyvinyl alcohol (PVA) used in industrial, commercial, healthcare and food sectors and used for the production of many end products such as varnishes, resins, surgical thread and food packaging materials, which are often in contact with food. This polymer is widely used for blending 
with other polymers to improve the mechanical properties of films obtained through joint structure and hydrophilic properties [2]. PVA is also widely used to produce nanocomposite materials, in particular based on aluminosilicate.

Currently, the focus in the field of layeredsilicate nanocomposites of polymer are paying a high level of exfoliation nanoscale particles in a polymer matrix that determines achieve high performance properties. Therefore, the actual problem is the selection of effective organic modifiers layered silicate that provide high adhesion filler with a polymer matrix. In this aspect, considerable interest is the study of the effect of various organic clay of the structure and properties of nanocomposites obtained, the nature of which is not yet fully understood [4]. Identifying these patterns allow to expand control over the structure and predict the properties of composite materials based organic clay.

\section{ANALYSIS OF RECENT RESEARCH}

One of the promising directions of polymer science and materials science in recent years is getting organic-inorganic polymer nanocomposites that have a predetermined set of properties $[10,12]$. Nanocomposites combine such chemical, physical and mechanical properties that cannot be achieved with the introduction of inorganic fillers of macro or microscopic structure.

Intercalation inorganic polymers in laminated materials, such as clay minerals - a promising new method of obtaining organic-inorganic nanostructures - supramolecular structures with specific molecular structure $[7,11]$. Such an approach causes multifaceted interest. Firstly, there is the practical ability to create layered nanocomposites. Secondly, its specific intercalation and its manifestation in acquiring systems improved physical and chemical properties are important. Furthermore, the study of these products can provide important information about the nature of chemical interactions in them, specific adsorption of polymers on nanoscale particles and so on.

Unfilled polyvinyl alcohol has a glass transition temperature of $70^{\circ} \mathrm{C}$ and a melting point of $225^{\circ} \mathrm{C}$. To fully intercalated materials (in which all polymer intercalated in the interlayer space of montmorillonite) based on PVA DSC results do not show any signs of Interphase temperature transitions between $35^{\circ} \mathrm{C}$ and $259^{\circ} \mathrm{C}$. Therefore, for ideally intercalated nanocomposites glass transition temperature and melting are impossible to determine by DSC because of very limited mobility of the polymer chains $[1,8,9]$.

In comparison to unfilled in PVA nanocomposites a new crystalline phase appears with a higher melting point. The resulting system has a dual melting point. Dual melting point of crystalline phases correspond to two: one formed mainly syndiotactic molecular chains, and the second mainly ataxic. The difference between the melting points of these crystals is about $15-22^{\circ} \mathrm{C}$. In MMT nanocomposites containing more than 5\% is present a sufficient number of unfilled polymer crystal structure and crystalline structure with a higher melting point, formed under the influence of inorganic silicate surfaces MMT [5, 14].

Stratified nanocomposites based on polymer and layered silicate have a higher thermal stability, resistance to solvents and resistance to different environments permeability compared to conventional filled materials. Due to dispersion of the filler at the nanoscale they are able to maintain light transmission of the polymer. In nanocomposites PVA/MMT, especially at low concentrations layered silicate $(<10 \%)$ suitable for industrial use, transmission electron microscopy and the number of simultaneous RPDA show intercalated simultaneously reveal the number and stratified silicate layers [15].

Nanocomposites PVA/MMT have a high light transmission even in the filler content, sufficient for the formation of layered nanocomposites. This is due to the dispersion of particles in a matrix layered silicate cover the nanoscale. Good light transmission allows using nanocomposite materials PVA/MMT for manufacturing paper coating simultaneously with unfilled PVA (which is used now). The presence of MMT particles does not affect the permeability of the composite for the visible spectrum (wavelength 400-700 $\mathrm{nm}$ ), so there is a high light transmission characteristic of unfilled PVA [3], but significantly increases atmospheric stability.

Previous research has developed a method to obtain water-soluble films based on PVA and montmorillonite-polyvinylpyrrolidone mixture (MPM), studied their performance properties [6, 13]. The aim of this study was to develop a method of producing structured water resistant films based on polyvinyl alcohol (PVA) and montmorillonite-polyvinylpyrrolidone mixture, investigate the impact of borax, MPM content and $\mathrm{pH}$ on the rheological properties of PVA solutions. 

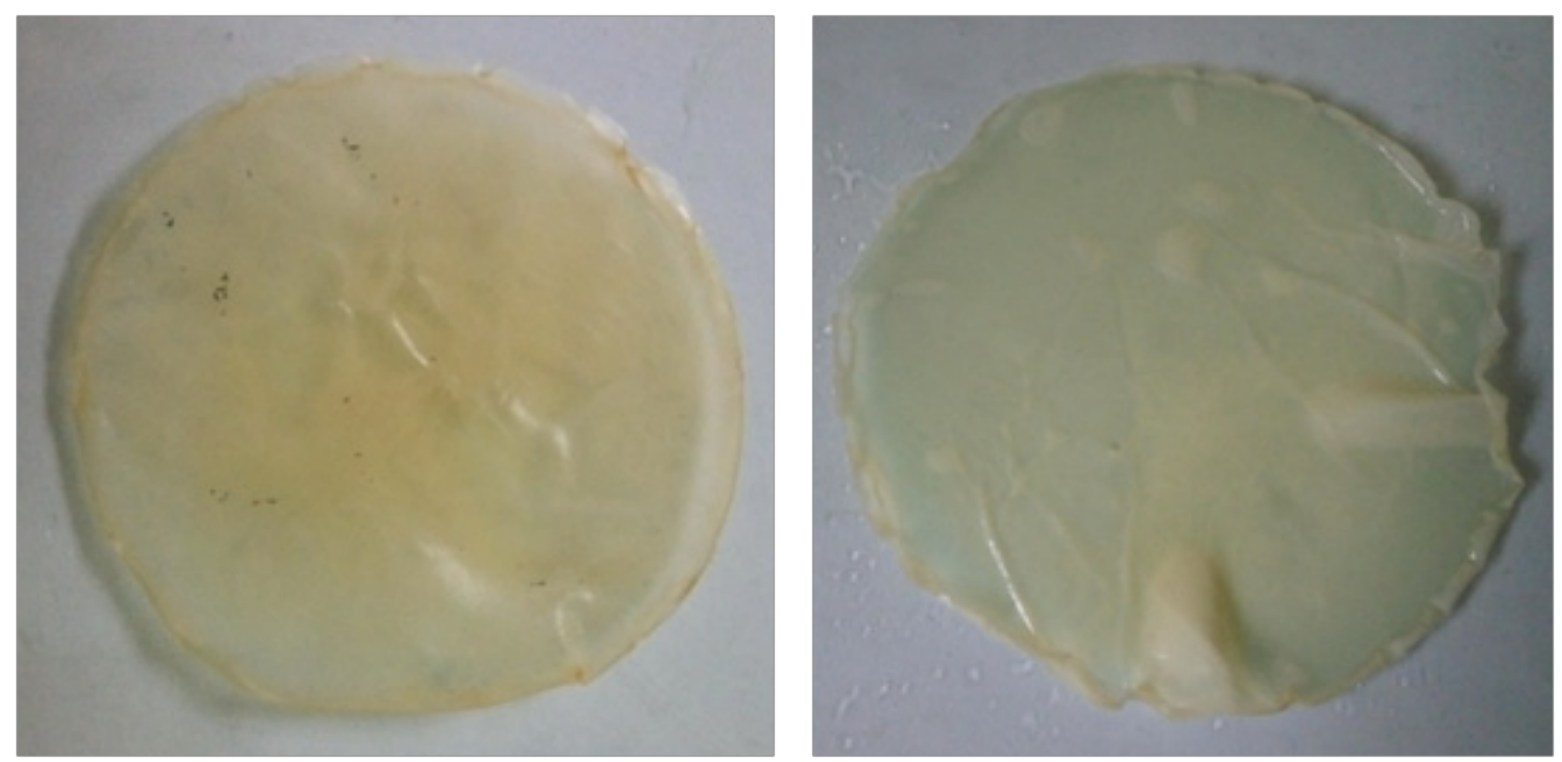

Fig. 1. Samples of films PVA: $\mathrm{MPM}=12: 1$

$\mathrm{a}$ - after heat treatment at $150^{\circ} \mathrm{C} ; \mathrm{b}$ - after the extracts in water for 24 hours

\section{RESEARCH METHODS}

PVA SUNDY 088-20 by Chinese company "Sinopec Sichuan Vinylon Works" (PVA 088-20, with viscosity $23 \mathrm{mPa} \cdot \mathrm{s}$ ) used for obtaining films. Prepared $8 \%$ solution of PVA in water and buffer solution with $\mathrm{pH} 4.4$ and 7.9. Dissolution was performed at $60^{\circ} \mathrm{C}$ using a magnetic stirrer. To the PVA resulting solution was added MPM in an amount that the ratio of elementary units of PVA to elementary parts PVP system was 16:1, 12:1, 8:1. The resulting mixture was treated with ultrasonic waves of a frequency of $22 \mathrm{kHz}$ on the machine "Volna UZTA 0.4/22 OM" for 3 minutes. Then the mixture was poured into special molds to produce films with plastic lining (to facilitate removal of the finished films form) and air-dried at room temperature. Finished films were separated from the

Table 1. Rheological properties of solutions of compositions $(\mathrm{pH}=7)$

\begin{tabular}{|c|c|c|c|c|c|}
\hline No. & $\mathrm{C}, \mathrm{g} / \mathrm{ml}$ & $\mathrm{T}, \mathbf{s}$ & $\eta_{\text {rel }}$ & $\eta_{\text {spec }}$ & [n] \\
\hline \multicolumn{6}{|c|}{ PVA 088-20 } \\
\hline 1 & 1.0 & 198.25 & 2.05 & 1.05 & \multirow{3}{*}{0.59} \\
\hline 2 & 0.50 & 139.75 & 1.42 & 0.42 & \\
\hline 3 & 0.25 & 113.44 & 1.17 & 0.17 & \\
\hline \multicolumn{6}{|c|}{ PVA 088-20: MPM = 12:1 } \\
\hline 1 & 1.0 & 221.50 & 2.29 & 1.29 & \multirow{3}{*}{0.63} \\
\hline 2 & 0.50 & 144.10 & 1.49 & 0.49 & \\
\hline 3 & 0.25 & 115.56 & 1.20 & 0.20 & \\
\hline \multicolumn{6}{|c|}{ PVA $088-20: M P M=12: 1$ of sodium tetraborate } \\
\hline 1 & 1.0 & 226.30 & 2.34 & 1.34 & \multirow{3}{*}{0.70} \\
\hline 2 & 0.50 & 146.51 & 1.52 & 0.52 & \\
\hline 3 & 0.25 & 117.26 & 1.22 & 0.22 & \\
\hline
\end{tabular}

*MPM - PVP:MMT = 5:1, while the net outflow of solvent (water) $-96.71 \mathrm{sec}$.

$\mathrm{C}$ - concentration of polymer in the solution, $\mathrm{g} / \mathrm{ml}$;

$\mathrm{t}$ - time leakage of the solution through capillary viscometer with capillary diameter of $0.56 \mathrm{~mm}$, sec;

$\eta_{\text {rel }}$ - relative viscosity of polymer solution;

$\eta_{\text {spec }}-$ specific viscosity of polymer solution;

$[\eta]-$ intrinsic viscosity. 
form and subjected to heat treatment strove at a temperature of $150^{\circ} \mathrm{C}$ for 30 minutes (Fig. 1).

Viscosimeterial study of aqueous solutions of PVA was performed using capillary viscometer (capillary diameter $-0.56 \mathrm{~mm}$ ). Research performed at $250.1^{\circ} \mathrm{C}$.

\section{RESULTS AND DISCUSSION}

For the research compositions based on PVA and MPM (PVP:MMT = 5:1) were used with the ratio of the number of elementary units of PVA to the number of PVP elementary units in and montmorillonite-polyvinylpyrrolidone mixture as 12:1.

The introduction of modifiers delivered in the processing solutions ultrasonic waves for 3 minutes because this method of mixing ensures satisfactory distribution of particles in the composition. Comparative results of research of the effect of $\mathrm{pH}$ and sodium tetraborate developed on the rheological properties of compositions are presented in Tables 1-3.

As we see, the lowest values of intrinsic viscosity regardless of environment marked by pure PVA solutions. The introduction of MPM to PVA solution leads to higher viscosity of compositions which can be explained by physical interaction of montmorillonite-polyvinylpyrrolidone mixture of polymer macromolecules in solution under the influence of ultrasound (evidenced by a slight change of color compositions).

It is logical that the highest viscosity solutions are characterized by compositions with traces of sodium tetraborate resulting from the formation of intermolecular chelate compounds by interaction of the -hydroxyl of PVA groups with borate-ions.
Evaluating the results presented in Tables 1-3, it can be concluded significant effect of $\mathrm{pH}$ on the viscosity of the solution of compositions. The lowest values observed intrinsic viscosity of the composition obtained in a neutral environment. Viscosity similar solution compositions in alkaline and acidic environments, virtually the same and is significantly higher.

With aim to determine the permeability and degree of structuring films based on modified PVA investigated their water absorption in cold water. The research results are presented in Table 4.

Without treating all the films based on modified PVA dissolved in water independently of $\mathrm{pH}$ in which they are received. After heat treatment at $150{ }^{\circ} \mathrm{C}$ for 30 minutes the film based on modified PVA only swell in water but not dissolved. From Table 4 we see that the lowest water absorption of film observed PVA:MPM = 12:1, produced in an acidic environment, which correlates well with the results of the mechanical strength of the films [13]. Thus, water absorption of films obtained in acidic medium, 2.5 times lower than the films obtained in a neutral environment. The films based compositions obtained in an alkaline environment also characterized by reduced water absorption, but after treating they were slightly yellow, which may indicate partial destruction of PVA. It is also worth noting that films based on PVA modified MPM characterized by lower water absorption than films based on PVA modified pure MMT. So the best environment to produce structured films based on modified PVA is acidic buffer solution, a modifier - MPM ratio PVA:MPM = 12:1 (the number of elementary units of PVA to PVP).

Table 2. Rheological properties of solutions of compositions ( $\mathrm{pH}=4.4)$

\begin{tabular}{|c|c|c|c|c|c|}
\hline No. & $\mathrm{C}, \mathrm{g} / \mathrm{ml}$ & T, s & $\eta_{\text {rel }}$ & $\eta_{\text {spec }}$ & [n] \\
\hline \multicolumn{6}{|c|}{ PVA 088-20 } \\
\hline 1 & 1 & 222.14 & 2.15 & 1.15 & \multirow{3}{*}{0.58} \\
\hline 2 & 0.5 & 148.84 & 1.45 & 0.45 & \\
\hline 3 & 0.25 & 122.21 & 1.18 & 0.18 & \\
\hline \multicolumn{6}{|c|}{ PVA 088-20: MPM = 12:1 } \\
\hline 1 & 1 & 236.25 & 2.29 & 1.29 & \multirow{3}{*}{0.91} \\
\hline 2 & 0.5 & 160.17 & 1.56 & 0.56 & \\
\hline 3 & 0.25 & 128.9 & 1.25 & 0.25 & \\
\hline \multicolumn{6}{|c|}{ PVA $088-20: M P M=12: 1$ of sodium tetraborate } \\
\hline 1 & 1 & 243.2 & 2.36 & 1.36 & \multirow{3}{*}{0.98} \\
\hline 2 & 0.5 & 166.34 & 1.62 & 0.62 & \\
\hline 3 & 0.25 & 131.85 & 1.28 & 0.28 & \\
\hline
\end{tabular}

* Time outflow of pure solvent (acid buffer solution) - $103 \mathrm{sec}$. 
Table 3. Rheological properties of solutions of compositions ( $\mathrm{pH}=7.9)$

\begin{tabular}{|c|c|c|c|c|c|}
\hline No. & $\mathrm{C}, \mathrm{g} / \mathrm{ml}$ & T, s & $\eta_{\text {rel }}$ & $\eta_{\text {spec }}$ & [n] \\
\hline \multicolumn{6}{|c|}{ PVA 088-20 } \\
\hline 1 & 1 & 236.17 & 2.26 & 1.26 & \multirow{3}{*}{0.65} \\
\hline 2 & 0.5 & 153.62 & 1.47 & 0.47 & \\
\hline 3 & 0.25 & 146.3 & 1.4 & 0.4 & \\
\hline \multicolumn{6}{|c|}{ PVA 088-20: MPM = 12:1 } \\
\hline 1 & 1 & 247.67 & 2.37 & 1.37 & \multirow{3}{*}{0.97} \\
\hline 2 & 0.5 & 167.2 & 1.6 & 0.6 & \\
\hline 3 & 0.25 & 131.6 & 1.26 & 0.26 & \\
\hline \multicolumn{6}{|c|}{ PVA $088-20: M P M=12: 1$ of sodium tetraborate } \\
\hline 1 & 1 & 256.03 & 2.45 & 1.45 & \multirow{3}{*}{0.11} \\
\hline 2 & 0.5 & 169.3 & 1.62 & 0.62 & \\
\hline 3 & 0.25 & 132.72 & 1.27 & 0.27 & \\
\hline
\end{tabular}

* Time outflow of pure solvent (alkaline buffer solution) - $104.5 \mathrm{sec}$.

\section{CONCLUSIONS}

Thus, experimental studies found that montmorillonite-polyvinylpyrrolidone mixture significantly affects the characteristics of the solution viscosity polyvinyl alcohol provided their mixing in the ultrasonic field. Composition of traces of sodium tetraborate in the aqueous solution of the highest rates of viscosity. Also on the viscosity of designed compositions, $\mathrm{pH}$ environment commits considerable influence, especially composition obtained in weakly alkaline environment with higher values of relative viscosity than compositions obtained in neutral and acidic environments. Simultaneously, water resistance and mechanical properties of films obtained in an acidic environment is best. The optimal from the standpoint of durability and water resistance is a composition of PVA:MPM=12:1 and depending on the content as MPM and $\mathrm{pH}$ characteristics of films based on PVA can be adjusted over a wide range, which would expand the scope.

Table 4. The water absorption of films based on modified PVA depending on the $\mathrm{pH}$ environment (heat treatment at $150^{\circ} \mathrm{C}$ )

\begin{tabular}{|c|c|c|c|}
\hline \multirow{2}{*}{$\begin{array}{c}\text { The composition } \\
\text { structure }\end{array}$} & \multicolumn{3}{|c|}{$\begin{array}{c}\text { The water absorption for } \mathbf{2 4} \\
\text { hours, \% by weight }\end{array}$} \\
\cline { 2 - 4 } & $\mathrm{pH}=7$ & $\mathrm{pH}=4.4$ & $\mathrm{pH}=7.9$ \\
\hline PVA: MPM $=16: 1$ & 219.66 & 82.56 & 86.15 \\
\hline PVA: MPM =12:1 & 186.26 & $\mathbf{7 6 . 2 3}$ & $\mathbf{8 3 . 2 3}$ \\
\hline PVA: $M P M=8: 1$ & 196.85 & 80.51 & 90.17 \\
\hline PVA:MMT=16:1 & 185.03 & 136.24 & 208.71 \\
\hline PVA:MMT=12:1 & 292.84 & 120.07 & 269.56 \\
\hline PVA:MMT=8:1 & $\mathbf{1 3 0 . 6 9}$ & $\mathbf{1 0 5 . 7 2}$ & $\mathbf{1 2 4 . 6 6}$ \\
\hline
\end{tabular}

\section{Acknowledgments}

The research leading to these results has received funding from the Ukrainian-budgetary Project 0116U004410 "Technology development for obtaining of constructional dispersed-filled polymer nanocomposites".

\section{REFERENCES}

1. Deng Chang, Lai Li-hui, Xu Jing, Shen Kai-zhi. Effect of Low Frequency Vibration on Property of PP/MMT Blends. Polymer Materials Science \& Engineering, 2006, 5, 178-181.

2. Gaaz T. S., Sulong A. B, et al.: Properties and Applications of Polyvinyl Alcohol, Halloysite Nanotubes and Their Nanocomposites. Molecules, 2015, 20 (12), 22833-22847; doi:10.3390/molecules201219884.

3. Han Bing, Cheng Aimin, Ji Gending, Wu ShiShan, Shen Jian. Effect of organophilic montmorillonite on polyurethane/montmorillonite nanocomposites. Journal of Applied Polymer Science, 2004, 91 (4), 2536-2542.

4. Havrylyuk N. A., Prykhod'ko H. P., Kartel' M. T.: Oderzhannya ta vlastyvosti nanokompozytiv na osnovi termoplastychnykh polimeriv, napovnenykh vuhletsevymy nanotrubkamy (Ohlyad). Poverkhnost, 2014, 204-240.

5. Heilmann A., Hamann C. Deposition, structure, and properties of plasma polymer metal composite films. Progress in Colloid and Polymer Science, 1991, 85, 102-110.

6. Krasinskyi V., Suberlyak O., Klym Y., Gajdos I.:. Innovative production of nanocomposites on the basis of thermoplastics and montmorillonite modified by polyvinylpirrolidone. XVII International 
Scientific Conference ,Trends and Innovative Approaches in Business Processes" (19 December 2014). SjF TU Košice, Slovak Republic, 2014, 1-6.

7. Krishnamoorti R., Vaia R.A.: Polymer Nanocomposites: Synthesis, Characterization, and Modelong. ACS Symp. Ser. 804. Washington DC. Am. Chem. Soc., 2001.

8. Kryszewski M. Nanointercalates - novel class of materials with promising properties. Synthetic Metals. 2000, 109, 47-54.

9. Nyhmatullyna A. Y., Vol'fson S. Y., Okhotyna N. A., Shaldybyna M. S.: Svoystva dynamycheskykh termoélastoplastovb soderzhashchykh modyfytsyrovannyy polypropylen y sloystyy napolnytel'. Bulletin of Kazan Technological University, 2010, 9, 329-333.

10. Olewnik E., Richert J.: Effect of the compatibilizing agent on the structure, mechanical and thermal properties of polylactide filled with modified and unmodified montmorillonite. Polymer Composites, 2014, 35, 1330-1337.
11. Pinnavaia T. J., Beall G.: Polymer-Clay-Nanocomposites. New York: Wiley, 2000.

12. Pomogailo A. D.: Synthesis and Intercalation Chemistry of Hybrid Organo-Inorganic Nanocomposites. Vysokomolekulyarnye soedineniya, 2006, 48 (7), 1318.

13. Suberlyak O., Krasinskyi V., Moravskyi V., Gerlach H., Jachowicz T. Influence of aluminosilicate filler on the physicomechanical properties of polypropylene-polycaproamide composites. Material Science, 2014, 50 (2), 296-302.

14. Zhou Li-juan, Zhao Ying, Yang Ming-shu,Wang Du-jin, Xu Duan-fu. Investigation on Photooxidative Degradation of Polypropylene / Organomontmorillonite Nanocomposites. Spectroscopy and Spectral Analysis. 2010, 30 (1), 109-113.

15. Zou En-guang, Wang Jian. Effect of high molecular weight tractive agent on the property of montmorillonite/polypropylene compound material. Journal of Daqing Petroleum Institute, 2009, 1, 56-59. 